\title{
MÍDIAS EXPERIMENTAIS
}

\author{
AUTOR: SAULO CARNEIRO PEREIRA DOS SANTOS \\ CO-AUTOR/ORIENTADOR: GUILHERME FOSCOLO DE MOURA GOMES
}

Resumo: O presente plano de trabalho teve como objetivo orientar o bolsista na produção dos materiais experimentais resultantes do projeto de pesquisa ao qual se vincula. $O$ estudante teve a oportunidade e foi ambientado com a constelação de textos pertinentes, que constam na bibliografia e que movimentaram o projeto de pesquisa. Para além do que estava descrito no plano de trabalho, houve o contato com outras demais referências bibliográficas, o que se deveu aos encontros do grupo de pesquisa, ao qual tanto o projeto de pesquisa quanto o bolsista estão vinculados. Desse modo, o bolsista também, foi familiarizado com a equipe de produção material/tecnológica ligada ao grupo de pesquisas avançadas em materialidades, ambiência e tecnologias (GPA-MAT), onde teve a oportunidade de realizar treinamento de atividade técnica de produção, mostra-se necessário salientar que, esse contato e atuação do bolsista abriram uma nova janela de possibilidades para uma maior imersão nos temas e objetos aos quais cada um dos momentos se referiam. Portanto, a participação do/da estudante no processo de pesquisa e produção teve como objetivos explorar como: I. as tecnologias constituem imagens e conformam os sentidos; II. as tecnologias produzem e reproduzem "pensamento» das próprias tecnologias; III. como interferir/sabotar/desviar as produções tecnológicas de uma estrutura que tecnologicamente se impõe. Assim, como um desdobramento desses objetivos a produção pode ser entendida como um fruto direto disto, sendo ela precedida por uma pré-produção, entendida como o momento que antecede o fazer, e se constituiu no espaço em que tudo que foi descrito no plano de trabalho se articulou a fim de resultar no imbricamento entre produção teórica e prática, resultado em um experimento teórico-ficcional-prático que é o podcast, ao qual o projeto se refere, entendido como ponto central nas encruzilhadas da pesquisa.

Palavras-chave: Mídias, Experimentais, Tecnologia. 